\title{
Social and Behaviour Change Communication Intervention Improves Coverage and Acceptance of Ivermectin Mass Drug Administration in Onchocerciasis Endemic Communities in Ghana: A Quasi Experimental Design
}

Francis Adjei Osei ( $\square$ francisph1@hotmail.com )

: Kwame Nkrumah University of Science and Technology School of Public Health

\section{Sam Newton}

Kwame Nkrumah University of Science and Technology

Isaac Nyanor

Kwame Nkrumah University of Science and Technology College of Health Sciences

Eugene Osei-Yeboah

Ghana Health Service

\section{Evans Xorse Amuzu}

Komfo Anokye Teaching Hospital

Nicholas Karikari Mensah

Komfo Anokye Teaching Hospital

Obed Ofori Nyarko

Komfo Anokye Teaching Hospital

\section{Ernest Amanor}

Komfo Anokye Teaching Hospital

\section{Samuel Frimpong Odoom}

Komfo Anokye Teaching Hospital

Suraj Yawnumah Abubakar

Komfo Anokye Teaching Hospital

Mathias Dongyele

Komfo Anokye Teaching Hospital

\section{Aliyu Mohammed}

Kwame Nkrumah University of Science and Technology College of Health Sciences

\section{Ofeibea Asare}

KNUST: Kwame Nkrumah University of Science and Technology

\section{Stephanie Boadi}

Komfo Anokye Teaching Hospital

\section{Peter Furu}

University of Copenhagen Department of Public Health: Kobenhavns Universitet Institut for Folkesundhedsvidenskab

\section{Dan Wolf Meyrowitsch}

University of Copenhagen Department of Public Health: Kobenhavns Universitet Institut for Folkesundhedsvidenskab

Ellis Owusu-Dabo

Kwame Nkrumah University of Science and Technology College of Health Sciences 


\section{Research Article}

Keywords: Social and Behaviour Change Communication, Onchocerciasis, Mass Drug Administration, Ghana Posted Date: October 27th, 2021

DOI: https://doi.org/10.21203/rs.3.rs-986375/v1

License: (c) (i) This work is licensed under a Creative Commons Attribution 4.0 International License. Read Full License 


\section{Abstract}

\section{Background}

Poor community awareness and social mobilization serve as a major barrier by increasing absenteeism and downplaying the relevance of the ivermectin mass distribution by community members. Inadequate awareness also creates confusion among community members especially when one intervention is mistaken for the other.

Methods

We designed a targeted Social and Behaviour Change Communication (SBCC) intervention with clearly defined and tailored messages of ivermectin MDA program targeting onchocerciasis in endemic communities in Ghana. Quasi experiment was conducted with a total sample size of 2008 at baseline and 2113 at endline.

Results

At baseline, $63.9 \%$ respondents did not receive Ivermectin during the previous year (2019) MDA programme and more than half of them (53.3\%) were not aware of the drug distribution. The communities that received the intervention at endline revealed a significantly higher increase in coverage (SATT $=0.123,95 \% \mathrm{Cl}=0.0 .073,0.173, p<0.001$ ). At baseline, uptake rate of $91.0 \%$ was recorded. Post the intervention, there was an increase in the proportion of respondents who ingested the MDA drugs (ivermectin) from $91.0 \%$ to $95.45 \%$. Previous uptake of MDA drugs (AOR=10.67; 95\%Cl: 5.59 $20.38, p<0.001)$, Perceived benefit of MDA drug (AOR=4.13; 95\% Cl: 1.69-10.15, $p<0.001)$ and being aware of the MDA programme $(A O R=2.28 ; 95 \% \mathrm{Cl}: 1.00-5.02, p=0.049)$ was associated with improved receipt of Ivermectin.

Conclusion

The findings of this study reveal that SBCC intervention improves ivermectin coverage and uptake rate in mass drug administration. Further research with technological innovations which can enhance SBCC is recommended taking hind sight of the limitations of the study due to the COVID-19 pandemic.

\section{Introduction}

Rapid urbanization and migration of registered indigenous people to cities have been found to contribute to a level of low mass drug administration (MDA) coverage as individuals in urban areas are difficult to track for medication in their homes. Also cross border migration and seasonal employment opportunities hinder the smooth implementation of MDA programs thus requiring more innovative ideas and strategies to reach targeted population (Hodges et al., 2010, 2012).

Inadequate community awareness of health programs is a major contributing factor affecting optimal utilisation of health services. Community awareness of health programs primarily aims at increasing knowledge, changing perceptions, attitudes, and motivating community members to mobilize to support and adopt a healthy intervention (Wight et al., 2015). Awareness creation and community led education messages are key to the success of MDA programs especially with combination of strategies targeting different segments in the population. The involvement of institutions such as churches, mosques, schools and other social societies play a central role in local education and serves as enablers for MDA programs (Dembélé et al., 2012; Richards et al. 2011). On the other hand, poor community awareness and social mobilization serve as a major barrier by increasing absenteeism and downplaying the relevance of the drug distribution by community members. Inadequate awareness also creates confusion among community members especially when one intervention is mistaken for the other. According to a study conducted by Agyemang et al. (2018), community members in an (?) onchocerciasis endemic district in Ghana misunderstood indoor residual insecticide spraying program (IRS) for malaria as a blackfly control thereby rejecting the MDA which accounted 
for low coverage. In an attempt to address such challenges, Social and behaviour change communication (SBCC) intervention targeting the focussed disease with clear messages has been recommended in other studies (Sodahlon et al., 2013).

Another strategy that has worked towards achieving success in implementing health programs is the school based health services where students are engaged as change agents. (Balassone et al., 1991; Anglin et al., 1996; Amaral et al., 2011). As mentioned by Mwanga et al. (2008), "If a child find his mother preparing food without washing hands, or coming from latrine and does not wash hands, he can tell her to wash hands. This would be a very useful advice". Areas that have seen tremendous success with school pupil as change agents includes diet control/physical activities, and handwashing. In a cluster randomized controlled to examine the effect of the child-initiated intervention on weight, physical activity and dietary habit of their mothers, the intervention was effective in motivating students to change their mothers' lifestyle in increasing physical activity and decreasing their mothers' weight (Gunawardena et al., 2016). A similar observation was in improvement in handwashing in a Tanzania study (Jensen, 2000; Jensen, 2002).

The current study designed a targeted Social and behaviour change communication (SBCC) intervention with clearly defined and tailored messages of Ivermectin MDA program targeting onchocerciasis in endemic communities. This was complemented by the adoption of a school-based helminth club and implemented in social events such as schools, churches, community information centres and use of info vans.

\section{Methods}

\section{Study design}

The study employed a quasi-experimental study design in two rural (Dabaa and Owabi) and two peri-urban (Koforidua and Ntensere) communities of the Atwima Nwabiagya North district. These were assigned to either an intervention or control group.

\section{Intervention}

Community members in the intervention group received health education which involved using video documentary, education in various community settings (churches, markets, mosques, health centres), customized t-shirts, school-based helminth clubs, posters and fliers. The Community Drug Distributors in this group received motivation in the form of increased allowance and training for two days on onchocerciasis and how Ivermectin works.

\section{Study type}

Mixed-method approach comprising of quantitative assessment of onchocerciasis and MDA (awareness, coverage, and compliance factors) followed by qualitative method to explore knowledge on onchocerciasis, enablers and barriers to MDA program from different stakeholders in the MDA program.

\section{Sample Size and Sampling}

The sample size was estimated using SBCC for improved Mass Drug Administration (MDA) for two controlled towns and two intervention towns. The sample size was estimated with anticipated coverage of $84.0 \%$ and a ratio of $1: 1$, a power of $80.0 \%$ to detect a difference of $5 \%$ with standard normal values of 1.96 which corresponds to $95 \%$ confidence interval.

\section{Sample size calculation}




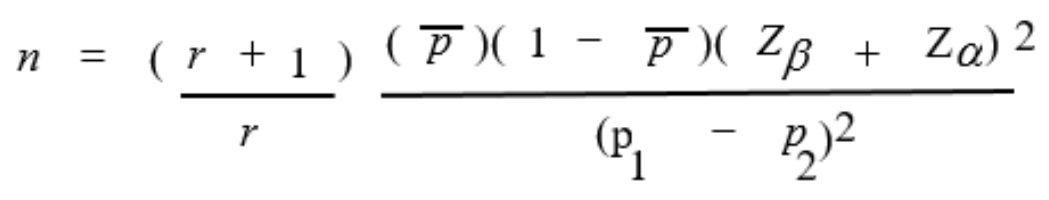

For $80 \%$ power, $Z=0.84$

For 0.05 significance level, Z=1.96 $(95 \% \mathrm{Cl})$

$r=1$ (equal number of interventions and controls)

The proportion of coverage of MDA for Ghana is 84\% in 2019 (Batsa Debrah et al., 2019).

$$
\bar{p}=\frac{0.84+0.79}{2}=0.815 \quad n=\frac{2(0.815)(0.185)(1.96+0.84)^{2}}{(0.05)^{2}} \quad \mathrm{n}=946
$$

Therefore, each arm comprised a sample size of 946.

Data collection and analysis

Household survey was conducted at baseline and post intervention MDA exercise (end-line).

An interviewer-based questionnaire was administered to heads and adults of each household within 30 clusters in four communities.

Concurrently, in-depth interviews were conducted with 19 key informants who were purposively selected on the basis of their role in the MDA campaign.

Eight (8) focus group discussions were also held with identifiable groups at baseline and at end line. Each FGD composed of 7-15 participants. The discussions focussed on community perception of MDA programs, awareness and social mobilization, Barriers to achieving adequate compliance and the extent of stakeholders' engagement and methods for undertaking monitoring and supervision. An interview guide was developed to support the qualitative interviews using In-depth Interviews and Focus Group Discussions techniques. All interviews were recorded on a voice recorder and were transcribed verbatim.

REDCap (version 11.3.2) was used to capture the quantitative data. The data were then imported into Stata (version 16 for analysis. For the qualitative approach, field notes were taken in addition to audio recordings and was transcribed. The transcripts of the qualitative interviews were imported into Nvivo 12 software for coding and analysis.

The effect of the intervention on the knowledge about onchocerciasis, awareness of MDA, coverage and compliance factors were assessed using logistic regression and Coarsened Exact Matching (CEM) technique. Frequencies were determined for the categorical variables whereas statistical estimations were done on the continuous variables and presented using charts and tables. Test of association was done using chi square estimates and bivariate logistics regression models.

Ethical considerations

Ethical approval was sought from the Committee on Human Research Publication and Ethics of the Kwame Nkrumah University of Science and Technology (Approval number: CHRPE/AP/001/19). In addition to this, clearance was also sought from the District Health Administration (DHA) of the Atwima Nwabiagya North District and the District Education 
Service. Permission from the respective leaders of the communities including the chief and community leaders was also sought. Once all these approvals were granted, at the household level, informed consent was obtained from the respondents. Participation was entirely voluntary. Written informed consent were sought to affirm the willingness of the respondents to participate.

Assumptions

The first assumption of the study was that respondents understand the questions asked and their answers were accurate and a true reflection of their onchocerciasis and MDA experiences. The second was that the selected study population was a true representation of the larger population.

\section{Results}

\section{Treatment effect of intervention on on whether respondents received MDA drugs or not (MDA coverage)}

As a proximate determinant of behaviour change and programme effect, MDA (ivermectin) coverage was assessed before and after the intervention. Generally, the coverage of MDA among the community members was low at baseline, with 36.1 having received the MDA during the previous round in 2019 prior to introducing the intervention $29.24 \%$ and $44.99 \%$ for intervention and control group, respectively as shown in figure 1 . On the other hand, the proportion of community members who received the MDA drugs (ivermectin) after the intervention had increased to $62.38 \%$. Community members who received the drugs in the 2020 round of MDA (after the intervention) was found to be higher for the intervention group (67.53\%) compared with the control group (56.22\%). (figure 1

Figure 1.: Coverage of MDA (Received or not received ivermectin) at baseline and endline

The descriptive results of MDA coverage pre- and post-intervention are summarized in Table 1Respondents who did not receive the drugs were halved from the endline compared to the baseline estimate (from $63.94 \%$ at pre-intervention to $37.62 \%$ at post-intervention. Regarding the reasons for not receiving the MDA drug, respondents not being aware of the drug distribution was the most cited with $34.11 \%$ with the intervention group recording $43.37 \%$ post-intervention, this reason reduced significantly.

Table 1: Descriptive assessment of predictors of coverage at Pre-Intervention and Post-Intervention in the study arms Although some few persons will not receive the drugs regardless of the amount of information you share with them, most people will likely accept it after being informed about the drug. Also, having an opinion leader in the team of educators positively influence the decision of community members to receive the medication.

"Previously, a lot of people used to refuse the drug but when I joined the team, it ceased and a lot more started taking the drug. There are only few people who have purposed in their heart to always refuse it irrespective of what we tell them.

They also restrain their children from taking it". (IDI, Opinion leader, Owabi)

The understanding of the contraindication of the drug was understood by community members post the intervention. As said by a community member, pregnant women are exempted from the drug during the campaign:

“.....it wasn't good for pregnant women so most of the pregnant women didn't take it when it was first shared but they took it this time because they have delivered already. Moreover, I think the number of people taking it this time has increased as compared to the previous years". (FGD, Community member, Owabi)

Improved drug coverage was attributable to the education in the sense that some misunderstandings were cleared. This 


\begin{tabular}{|c|c|c|c|c|c|c|c|}
\hline \multirow[t]{2}{*}{ Variables } & \multicolumn{3}{|c|}{ Pre-Intervention } & \multicolumn{4}{|c|}{ Post-Intervention } \\
\hline & $\begin{array}{l}\text { Intervention } \\
\text { arm, } \\
n=1139(\%)\end{array}$ & $\begin{array}{l}\text { Control } \\
\text { arm, } \\
n=869(\%)\end{array}$ & $\begin{array}{l}\text { Total, } \\
\mathrm{n}=2008(\%)\end{array}$ & $\begin{array}{l}\text { Intervention } \\
\text { arm, } \\
n=1149(\%)\end{array}$ & $\begin{array}{l}\text { Control } \\
\text { arm, } \\
n=964(\%)\end{array}$ & $\begin{array}{l}\text { Total, } \\
\mathrm{n}=2113(\%)\end{array}$ & $\begin{array}{l}\chi 2(p- \\
\text { value })\end{array}$ \\
\hline \multicolumn{8}{|l|}{$\begin{array}{l}\text { CDD offered } \\
\text { MDA drug to } \\
\text { respondents }\end{array}$} \\
\hline No & 791(69.45) & 457(52.59) & $1248(62.15)$ & $328(28.55)$ & 415(43.05) & 743(35.16) & $<0.001$ \\
\hline Yes & $348(30.55)$ & $412(47.41)$ & $760(37.85)$ & $821(71.45)$ & $549(56.95)$ & $1370(64.84)$ & \\
\hline \multicolumn{8}{|l|}{$\begin{array}{l}\text { Did } \\
\text { respondents } \\
\text { receive MDA } \\
\text { drugs? }\end{array}$} \\
\hline No & 806(70.76) & 478(55.01) & 1284(63.94) & $374(32.47)$ & 422(43.78) & 796(37.62) & $<0.001$ \\
\hline Yes & $333(29.24)$ & $391(44.99)$ & 724(36.06) & 778(67.53) & $542(56.22)$ & $1320(62.38)$ & \\
\hline \multicolumn{8}{|l|}{$\begin{array}{l}\text { Reasons for } \\
\text { not receiving } \\
\text { the drug }\end{array}$} \\
\hline $\begin{array}{l}\text { Absent from } \\
\text { home }\end{array}$ & 159(13.96) & 165(18.99) & $324(16.14)$ & 193(16.75) & $224(23.24)$ & 417(19.71) & $<0.001$ \\
\hline $\begin{array}{l}\text { CDD did not } \\
\text { come to the } \\
\text { house }\end{array}$ & 199(17.47) & $77(8.86)$ & 276(13.75) & $58(5.03)$ & 113(11.72) & $171(8.08)$ & $<0.001$ \\
\hline $\begin{array}{l}\text { Shortage of } \\
\text { drugs }\end{array}$ & $9(0.79)$ & $1(0.12)$ & $10(0.50)$ & $2(0.17)$ & $1(0.10)$ & $3(0.14)$ & 0.671 \\
\hline $\begin{array}{l}\text { Taking } \\
\text { chronic } \\
\text { medication }\end{array}$ & $7(0.61)$ & $2(0.23)$ & $9(0.45)$ & $4(0.35)$ & 18(1.87) & $22(1.04)$ & 0.001 \\
\hline $\begin{array}{l}\text { Not aware of } \\
\text { drug } \\
\text { distribution }\end{array}$ & 494(43.37) & 191(21.98) & 685(34.11) & $5(0.43)$ & $14(1.45)$ & $19(0.90)$ & 0.013 \\
\hline Was pregnant & $26(2.28)$ & $16(1.84)$ & $42(2.09)$ & $29(2.52)$ & $40(4.15)$ & $69(3.26)$ & 0.035 \\
\hline $\begin{array}{l}\text { CDD did not } \\
\text { come to the } \\
\text { community }\end{array}$ & $40(3.51)$ & $35(4.03)$ & 75(3.74) & $11(0.95)$ & $3(0.31)$ & $14(0.66)$ & 0.069 \\
\hline $\begin{array}{l}\text { Drugs not } \\
\text { offered to me }\end{array}$ & $48(4.21)$ & $32(3.68)$ & $80(3.98)$ & $14(1.22)$ & $11(1.14)$ & $25(1.18)$ & 0.875 \\
\hline Do not know & $36(3.16)$ & $12(1.38)$ & $48(2.39)$ & $40(3.47)$ & $3(0.31)$ & $43(2.03)$ & $<0.001$ \\
\hline
\end{tabular}

was reflected in the quote:

"I think it has increase because all those who were not liable to take it in the first MDA exercise can take it now and the education has also helped clear some negative ideas people had about the drugs". (FGD, Community member, Owabi

Using Coarsened Exact Matching (CEM) technique, the logit model used to assess the effect of the intervention on MDA coverage showed statistically significant estimate of the effect at pre-intervention compared with the post-intervention estimate as shown intable 2. The effect of the intervention at endline revealed a significantly higher increase 
in coverage $(\mathrm{SATT}=0.123,95 \% \mathrm{Cl}=0.0 .073,0.173)$. This means that, among the intervention group, receiving the intervention likely increased the MDA coverage among community members by $12.3 \%$. This significant difference would have not been the situation if the community members had not received the MDA SBCC intervention.

Table 2: Sample Average Treatment effect on the Treated (SATT) of intervention on geographical coverage of ivermectin MDA against onchocerciasis

\begin{tabular}{|llll|}
\hline Coverage & SATT & SE & $95 \% \mathrm{Cl}$ \\
\hline Baseline & 0.051 & 0.022 & $(0.008,0.093)^{\star}$ \\
\hline Endline & 0.123 & 0.026 & $0.073,0.173)^{\star \star \star}$ \\
\hline
\end{tabular}

*indicates $p<0.05, * * *$ significant at $p<0.001$

Source: Field Data, 2020

In order to estimate the overall impact of the intervention on the ivermectin drug coverage, the difference-in-difference model was used to account for the non-parallel modification before and after introducing the intervention between the intervention and control group as shown intable 3. There was no significant difference of the intervention on MDA coverage (Diff $=-0.049, t=1.48, \mathrm{p}=<0.139)$.

Table 3Effect of intervention on ivermectin MDA coverage with DiD using Kernel Propensity Score

\begin{tabular}{|lllll|}
\hline Outcome variable & Hlvermectin MDA Coverage & SE & t & p value \\
\hline Baseline & & & & \\
\hline Control & 0.466 & & & \\
\hline Intervention & 0.606 & 0.024 & 5.87 & $0.000^{\star \star \star}$ \\
\hline Diff (I-C)b & 0.14 & & & \\
\hline Endline & & & & \\
\hline Control & 0.398 & & & \\
\hline Intervention & 0.489 & 0.023 & 3.96 & $0.000^{\star \star \star}$ \\
\hline Diff (I-C)e & 0.091 & 0.033 & 1.48 & 0.139 \\
\hline Diff-in-Diff[I-C)e-(I-C)b] & -0.049 & & & \\
\hline
\end{tabular}

*indicates $p<0.05, * *$ significant at $p<0.01, * * *$ significant at $p<0.001 ;$ I=Intervention and C=Control; +Model adjusted for age, sex, marital status, occupation, education and household wealth index

Source: Field Data, 2020

The results of bivariate and multivariate analysis regarding predictors for whether the respondents received the drugs or not among respondents in the intervention group pre and post the intervention. The results are presented in Table 4. The odds ratios indicate the likelihood of receiving the MDA drugs from the CDD. Having adequate knowledge about onchocerciasis ( $\mathrm{aOR}=1.82,95 \% \mathrm{Cl}=1.37-2.43)$, respondents who perceive the MDA drug as beneficial $(\mathrm{aOR}=6.33,95 \%$ $\mathrm{Cl}=3.41-11.75)$, participation in previous MDA campaigns ( $\mathrm{aOR}=1.59,95 \% \mathrm{Cl}=1.22-2.09)$ and being aware of the MDA program (aOR=2.24, 95\% Cl=1.59-3.15) significantly increase the odds of receiving the MDA drugs. (Table 4) 
Table 4.: Bivariate and multivariate logistic regression of intervention effect on whether respondents received MDA drugs or not 
Factor

Baseline

Endline

$\operatorname{cOR}(95 \% \mathrm{Cl}) \quad$ aOR $(95 \% \mathrm{Cl}) \quad \operatorname{cOR}(95 \% \mathrm{Cl}) \quad$ aOR $(95 \% \mathrm{Cl})$

Age category (years)

\begin{tabular}{lllll}
$18-29$ & Ref & Ref & Ref & Ref \\
\hline $30-39$ & $0.79(0.60-1.04)$ & $0.61(0.41-0.91) *$ & $1.33(0.99-1.79)$ & $1.46(0.98-2.17)$ \\
\hline $40-49$ & $0.83(0.61-1.15)$ & $0.74(0.46-1.19)$ & $1.54(1.10-2.14) *$ & $1.70(1.06-2.72)^{\star}$ \\
\hline $50-59$ & $0.58(0.36-0.93) *$ & $\begin{array}{l}0.39(0.20-0.77) \\
\star *\end{array}$ & $2.36(1.38-4.04) * *$ & $1.98(1.06-3.72)^{\star}$ \\
\hline $60+$ & $\begin{array}{l}0.53(0.37-0.77) \\
* *\end{array}$ & $0.55(0.31-0.95) *$ & $1.94(1.23-3.06) * *$ & $1.91(1.11-3.27)^{\star}$
\end{tabular}

Sex

\begin{tabular}{lllll} 
Male & Ref & Ref & Ref & Ref \\
\hline Female & $1.08(0.5-1.37)$ & $0.84(0.63-1.14)$ & $1.22(0.97-1.54)$ & $1.15(0.88-1.50)$
\end{tabular}

Marital status

Single/widowed/divorced

Ref Ref Ref Ref

Living with spouse

$1.11(0.89-1.37) \quad 1.24(0.89-1.71) \quad 1.23(0.95-1.58) \quad 0.85(0.59-1.20)$

Occupation

Unemployed

Skilled labour

Ref

Ref

Ref

Ref

Skilled labour

$1.89(1.35-2.64)$

$1.17(0.76-1.82)$

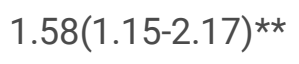

$1.41(0.98-2.02)$

Unskilled labour

$0.80(0.63-1.01)$

$0.94(0.65-1.35)$

$1.49(1.13-1.98)^{\star \star}$

$1.12(0.78-1.61)$

\section{Educational status}

\begin{tabular}{lllll} 
No formal education & Ref & Ref & Ref & Ref \\
\hline Basic & $1.40(1.02-1.94) *$ & $1.07(0.69-1.67)$ & $0.67(0.39-1.16)$ & $1.19(0.66-2.13)$ \\
\hline Secondary and above & $\begin{array}{l}1.69(1.18-2.43) \\
\star *\end{array}$ & $0.97(0.58-1.61)$ & $0.82(0.48-1.42)$ & $1.49(0.80-2.77)$
\end{tabular}

Household Wealth Index

\begin{tabular}{lllll} 
Low quintile & Ref & Ref & Ref & Ref \\
\hline High quintile & $1.43(1.15-1.77)$ & $1.40(1.06-1.85) *$ & $1.51(1.21-1.88) * * *$ & $1.19(0.92-1.53)$
\end{tabular}

Duration of stay in the

Community

\begin{tabular}{lllll}
\hline Up to ten years & Ref & Ref & Ref & Ref \\
\hline More than ten years & $\begin{array}{l}0.71(0.57- \\
0.89)^{\star \star}\end{array}$ & $0.86(0.63-1.11)$ & $1.22(0.98-1.53)$ & $1.21(0.93-1.58)$ \\
\hline
\end{tabular}

Ever heard of Oncho

No

Ref

Ref

Ref

Ref 


\section{Knowledge of Oncho}

$\begin{array}{lllll}\text { Inadequate } & \text { Ref } & \text { Ref } & \text { Ref } & \text { Ref } \\ \text { Adequate } & 0.46(0.36- & 0.60(0.43-0.84) & 2.71(2.16-3.41) * * * & 1.82(1.37-2.43) \\ & 0.60)^{\star \star *} & * \star & & \end{array}$

\section{Aware of MDA}

\begin{tabular}{lllll} 
No & Ref & Ref & Ref & Ref \\
\hline Yes & $0.06(0.04-$ & $0.15(0.10-0.21)$ & $4.56(3.46-6.01)$ & $2.24(1.59-$ \\
& $0.09)^{\star \star \star}$ & $* \star \star$ & $\star \star \star *$ & $3.15)^{\star \star \star}$
\end{tabular}

\section{MDA drug beneficial}

\begin{tabular}{lllll} 
No & Ref & Ref & Ref & Ref \\
\hline Yes & $\begin{array}{ll}0.36(0.24- \\
0.54)^{\star \star \star}\end{array}$ & $0.76(0.48-1.20)$ & $4.56(3.46-6.01)^{\star \star \star}$ & $\begin{array}{c}6.33(3.41- \\
11.75)^{\star \star \star}\end{array}$ \\
\hline Participated in previous MDA & & & & \\
No & Ref & Ref & Ref & Ref \\
Yes & $\begin{array}{lll}0.10(0.07- \\
0.12)^{\star \star \star}\end{array}$ & $\begin{array}{l}0.17(0.12-0.23) \\
\star \star \star\end{array}$ & $\begin{array}{l}15.07(8.44-26.88) \\
\star \star \star\end{array}$ & $1.59(1.22-2.09)^{\star \star}$
\end{tabular}

*indicates $p<0.05,{ }^{* *}$ significant at $p<0.01,{ }^{* *}$ significant at $p<0.001$

Overall, the MDA compliance (uptake rate) among the community members was high at pre-intervention, with $91.02 \%$ having ingested the MDA drugs they received during the previous round in 2019 prior to introducing the intervention $88.29 \%$ and $93.35 \%$ for intervention and control group, respectively as shown in figure 2Post the intervention, the proportion of respondents who ingested the MDA drugs (ivermectin) they received increased to $95.45 \%$. Respondents who received the drugs in the 2020 round of MDA (post-intervention) was found to be higher for the intervention group (97.36\%) compared with the control group (92.76\%). (figure 2)

Figure 2: Compliance (uptake of ivermectin) at baseline and endline

Table 5provides further description of compliance (drug uptake) variables in the study arms at baseline and endline. It was observed that the proportion of respondents who swallowed the drugs in the presence of the CDD improved in the intervention group at endline (from $80.61 \%$ at baseline to $85.70 \%$ at endline). There was a significant improvement in the uptake of the drug among household members. At baseline, $29 \%$ of the respondents in the intervention group indicated that all members in their households swallowed the MDA drug. This proportion increased to $66.06 \%$ at endline. Other variables assessed such as MDA drug being beneficial also saw improvement from 41.70 at baseline to $72.41 \%$ at endline. (Table 5))

Table 5: Baseline and endline assessment of respondents regarding compliance to MDA 
Variables

Baseline

Endline

\begin{tabular}{|c|c|c|c|}
\hline $\begin{array}{l}\text { tervention, } \\
=333(\%)\end{array}$ & $\begin{array}{l}\text { Control, } \\
n=391(\%)\end{array}$ & $\begin{array}{l}\text { Total, } \\
n=724(\%)\end{array}$ & $\begin{array}{l}\text { Intervention, } \\
\mathrm{n}=796(\%)\end{array}$ \\
\hline
\end{tabular}

\section{Did}

respondents

swallow the

MDA drug?

\begin{tabular}{|c|c|c|c|c|c|c|c|}
\hline No & $39(11.71)$ & $26(6.65)$ & $65(8.98)$ & $21(2.64)$ & $41(7.24)$ & $62(4.55)$ & $<0.001$ \\
\hline Yes & 294(88.29) & $365(93.35)$ & 659(91.02) & 775(97.36) & $525(92.76)$ & $1300(95.45)$ & \\
\hline \multicolumn{8}{|l|}{$\begin{array}{l}\text { Time drug was } \\
\text { swallowed }\end{array}$} \\
\hline $\begin{array}{l}\text { In presence of } \\
\mathrm{CDD}\end{array}$ & 237(80.61) & $280(76.71)$ & $517(78.45)$ & $665(85.70)$ & $465(88.40)$ & 1130(86.79) & 0.157 \\
\hline $\begin{array}{l}\text { Swallowed } \\
\text { later the same } \\
\text { day }\end{array}$ & $37(64.91)$ & $66(77.65)$ & 103(72.54) & $69(63.89)$ & $48(64.86)$ & $117(64.29)$ & 0.893 \\
\hline $\begin{array}{l}\text { Swallowed it } \\
\text { the following } \\
\text { day }\end{array}$ & $20(35.09)$ & $19(22.35)$ & $39(27.46)$ & $39(36.11)$ & 26(35.14) & $65(35.71)$ & \\
\hline
\end{tabular}

\section{Reasons for swallowing drug ( $\mathrm{N}=$ Yes figure)}

\begin{tabular}{|c|c|c|c|c|c|c|c|}
\hline $\begin{array}{l}\text { To prevent } \\
\text { onchocerciasis }\end{array}$ & 206(18.09) & $274(31.53)$ & $480(23.90)$ & 757(65.71) & $434(45.02)$ & 1191(56.29) & $<0.001$ \\
\hline $\begin{array}{l}\text { To improve my } \\
\text { health }\end{array}$ & $66(5.79)$ & $52(5.98)$ & $118(5.88)$ & $69(5.99)$ & 183(18.98) & 252(11.91) & $<0.001$ \\
\hline $\begin{array}{l}\text { I complied } \\
\text { with } \\
\text { instructions }\end{array}$ & $42(3.69)$ & $60(6.90)$ & 102(5.08) & 19(1.65) & $90(9.34)$ & $109(5.15)$ & $<0.001$ \\
\hline Do not know & $9(0.79)$ & 11(1.27) & $20(1.00)$ & $9(0.78)$ & $7(0.73)$ & $16(0.75)$ & 0.884 \\
\hline \multicolumn{8}{|l|}{$\begin{array}{l}\text { Reasons for } \\
\text { not } \\
\text { swallowing the } \\
\text { drug }(N=65)\end{array}$} \\
\hline $\begin{array}{l}\text { Respondents } \\
\text { not at risk }\end{array}$ & $4(0.35)$ & $1(0.12)$ & $5(0.25)$ & $18(1.56)$ & 19(1.97) & $37(1.75)$ & 0.475 \\
\hline $\begin{array}{l}\text { Drug not } \\
\text { effective }\end{array}$ & $2(0.18)$ & $0(0.0)$ & $2(0.10)$ & 1(0.09) & $2(0.21)$ & $3(0.14)$ & 0.463 \\
\hline $\begin{array}{l}\text { Fear of side } \\
\text { effect }\end{array}$ & $19(1.67)$ & $12(1.38)$ & $31(1.54)$ & $18(1.56)$ & $29(3.01)$ & $47(2.22)$ & 0.025 \\
\hline Pregnancy & $2(0.18)$ & $5(0.58)$ & $7(0.35)$ & $28(2.43)$ & $23(2.39)$ & $51(2.41)$ & 0.947 \\
\hline $\begin{array}{l}\text { Had taken } \\
\text { alcohol }\end{array}$ & $1(0.09)$ & $0(0.0)$ & $1(0.05)$ & $4(0.35)$ & $3(0.31)$ & $7(0.33)$ & 0.886 \\
\hline $\begin{array}{l}\text { Do not trust } \\
\text { the CDD }\end{array}$ & $7(0.61)$ & $6(0.69)$ & $13(0.65)$ & $4(0.35)$ & $1(0.10)$ & $5(0.24)$ & 0.251 \\
\hline
\end{tabular}




\begin{tabular}{llllllll}
$\begin{array}{l}\text { Faith/religious } \\
\text { beliefs }\end{array}$ & $0(0.0)$ & $0(0.0)$ & $0(0.0)$ & $1(0.09)$ & $0(0.00)$ & $1(0.05)$ & 0.36 \\
\hline Other & $11(0.97)$ & $6(0.69)$ & $17(0.85)$ & $83(7.20)$ & $32(3.32)$ & $115(5.43)$ & $<0.001$
\end{tabular}

\section{Household members that took the drug}

\begin{tabular}{|c|c|c|c|c|c|c|}
\hline $\begin{array}{l}\text { Everyone in } \\
\text { the household }\end{array}$ & 184(16.15) & 296(34.06) & $480(23.90)$ & $439(38.21)$ & $412(42.74)$ & $851(40.27)$ \\
\hline $\begin{array}{l}\text { Few people in } \\
\text { the household }\end{array}$ & $200(17.56)$ & 136(15.65) & $336(16.73)$ & $363(31.59)$ & $275(28.53)$ & 638(30.19) \\
\hline $\begin{array}{l}\text { Nobody in the } \\
\text { household }\end{array}$ & $243(21.33)$ & 114(13.12) & $357(17.78)$ & $59(5.13)$ & 153(15.87) & $212(10.03)$ \\
\hline Do not know & $512(44.95)$ & $323(37.17)$ & $835(41.58)$ & $288(25.07)$ & $124(12.86)$ & $412(19.50)$ \\
\hline
\end{tabular}

\section{Did all recipients in the household members swallow the drug}

\begin{tabular}{llllllll} 
No & $745(70.95)$ & $406(53.63)$ & $1151(63.70)$ & $390(33.94)$ & $470(48.76)$ & $860(40.70)$ & $<0.001$ \\
\hline Yes & $305(29.05)$ & $351(46.37)$ & $656(36.30)$ & $759(66.06)$ & $494(51.24)$ & $1253(59.30)$
\end{tabular}

\section{Any \\ discomfort after taking the drug?}

\begin{tabular}{llllllll} 
No & $250(85.03)$ & $338(92.60)$ & $588(89.23)$ & $730(94.44)$ & $488(92.78)$ & $1218(93.76)$ & 0.224 \\
\hline Yes & $44(14.97)$ & $27(7.40)$ & $71(10.77)$ & $43(5.56)$ & $38(7.22)$ & $81(6.24)$ &
\end{tabular}

\section{Discomfort \\ identified by \\ respondents \\ ( $n=$ Yes figure)}

\begin{tabular}{llllllll} 
Nausea & $15(1.32)$ & $11(1.27)$ & $26(1.29)$ & $16(1.39)$ & $24(2.49)$ & $40(1.89)$ & 0.064 \\
\hline Swelling & $2(0.18)$ & $7(0.81)$ & $9(0.45)$ & $4(0.35)$ & $1(0.10)$ & $5(0.24)$ & 0.251 \\
\hline Headache & $6(0.53)$ & $3(0.35)$ & $9(0.45)$ & $25(2.17)$ & $5(0.52)$ & $30(1.42)$ & 0.001 \\
\hline Rashes & $5(0.44)$ & $8(0.92)$ & $13(0.65)$ & $2(0.17)$ & $5(0.52)$ & $7(0.33)$ & 0.169 \\
\hline Other & $21(1.84)$ & $2(0.23)$ & $23(1.15)$ & $13(1.13)$ & $11(1.14)$ & $24(1.13)$ & 0.978 \\
\hline
\end{tabular}

\section{MDA drug is beneficial than discomfort}

\begin{tabular}{llllllll} 
Agree & $475(41.70)$ & $438(50.40)$ & $913(45.47)$ & $832(72.41)$ & $679(70.44)$ & $1511(71.51)$ & 0.591 \\
\hline Disagree & $8(0.70)$ & $7(0.81)$ & $15(0.75)$ & $8(0.70)$ & $8(0.83)$ & $16(0.76)$ \\
\hline Do not know & $656(57.59)$ & $424(48.79)$ & $1080(53.78)$ & $309(26.89)$ & $277(28.73)$ & $586(27.73)$
\end{tabular}


MDA to be

beneficial?

\begin{tabular}{llllllll}
\hline No & $145(13.94)$ & $133(17.07)$ & $278(15.28)$ & $77(6.70)$ & $81(8.40)$ & $158(7.48)$ & 0.139 \\
\hline Yes & $895(86.06)$ & $646(82.93)$ & $1541(84.72)$ & $1072(93.30)$ & $883(91.60)$ & $1955(92.52)$ &
\end{tabular}

\section{Do you think \\ the MDA drug \\ is beneficial?}

\begin{tabular}{llllllll}
\hline No & $145(13.94)$ & $133(17.07)$ & $278(15.28)$ & $77(6.70)$ & $81(8.40)$ & $158(7.48)$ & 0.139 \\
\hline Yes & $895(86.06)$ & $646(82.93)$ & $1541(84.72)$ & $1072(93.30)$ & $883(91.60)$ & $1955(92.52)$ &
\end{tabular}

Don't know

Will
respondents
accept the
MDA drug if it
is to be given
instantly?

\begin{tabular}{llllllll}
\hline No & $683(59.69)$ & $395(45.45)$ & $1078(53.69)$ & $115(10.02)$ & $265(27.52)$ & $380(18.00)$ & $<0.001$ \\
\hline Yes & $456(40.04)$ & $474(54.55)$ & $930(46.31)$ & $1033(89.98)$ & $698(72.48)$ & $1731(82.00)$ &
\end{tabular}

\section{Respondents to encourage others to take MDA}

\begin{tabular}{llllllll} 
Yes & $1008(90.08)$ & $764(89.78)$ & $1772(89.95)$ & $1047(91.20)$ & $871(90.35)$ & $1918(90.81)$ & 0.501 \\
\hline No & $111(9.92)$ & $87(10.22)$ & $198(10.05)$ & $101(8.80)$ & $93(9.65)$ & $194(9.19)$ &
\end{tabular}

\section{Ever participated in the previous MDA?}

\begin{tabular}{llllllll}
\hline No & $126(11.29)$ & $86(10.15)$ & $212(10.80)$ & $569(49.52)$ & $453(46.99)$ & $1022(48.37)$ & 0.246 \\
\hline Yes & $990(88.71)$ & $761(89.85)$ & $1751(89.20)$ & $580(50.48)$ & $511(53.01)$ & $1091(51.63)$ &
\end{tabular}

The evidence that the intervention has impacted on the increased acceptance was confirmed in the qualitative study conducted post-intervention. In a post-intervention assessment, a community member said:

"For me when they bring it every year, I drink it. Because how they explained it entices me to drink it and I would want everyone to drink it because blindness is a terrible sickness". (FGD, Community member, Koforidua)

A community member gave an indication that he will swallow the drug when given next year. It was reflected in this quote:

"This is the second time and by God's grace I've drunk some. It came last year 2019 and this year 2020 it has come and by God's grace I've drunk some and I'm looking forward to be taking it the next year". (FGD, Community member, Koforidua)

A community member taking ivermectin for the first time explained the circumstance which almost blurred his desire to accept the drug. However, due to the education received on the MDA, there was a change of mind to comply. 
"I have also taken some only this year. For me, when they shared it to some of the students, some complained they were feeling drowsy so I didn't want to take it but I had some faith in it and took it when they came here and explained it to me". (FGD, Community member, Koforidua)

Perceived severity (a component of the educational intervention) of the disease was the reason why some community members complied with the medications when it was offered. This was reflected in the quote

"Yes, they told us the disease can lead to blindness and that is what pushed me to take the drugs". (FGD, Community member, Owabe)

Also, perceived susceptibility (which was a key component in the intervention put in place was the reason why another person swallowed the drug offered.

"What motivates me to take the drug is the education given to us concerning the onchocerciasis. I took the drugs so that I don't contract the disease". [FGD, Community member, Owabi]

The CEM technique used to assess effect effect of the intervention on compliance (drug uptake) showed a statistically significant effect of the intervention at post-intervention compared with the baseline estimate as shown in Table 4. 22. The effect of the intervention showed a significant increase in drug uptake (SATT $=0.054,95 \% \mathrm{Cl}=0.0 .013,0.095)$. In summary, in the intervention group, receiving the intervention likely increased the drug uptake among community members by $5.4 \%$. This significant difference may be attributed to the MDA SBCC intervention.

Table 6: Sample Average Treatment effect on the Treated (SATT) of intervention on drug uptake rate of ivermectin MDA against onchocerciasis

\begin{tabular}{|llll|}
\hline Compliance & SATT & SE & $95 \%$ Cl \\
\hline Pre-Intervention & $(-0.024)$ & 0.02 & $(-0.062,0.014)$ \\
\hline Post-Intervention & 0.054 & 0.021 & $(0.013,0.095)^{\star}$ \\
\hline
\end{tabular}

*indicates $p<0.05$

Source: Field Data, 2020

In order to estimate the overall impact of the intervention on ivermectin uptake rate, the difference-in-difference model was used to account for the non-parallel modification before and after introducing the intervention between the intervention and control group as shown inTable 6 . The overall impact of the intervention revealed a statistically significant improvement in ivermectin uptake rate by $6.8 \%$ (Diff $=-0.068, t=3.06, \mathrm{p}=0.002)$.

Table 7: tModel adjusted for age, sex, marital status, occupation, education and household wealth index 


\begin{tabular}{|lllll|}
\hline Outcome variable & Hlvermectin uptake rate & SE & t & p value \\
\hline Baseline & & & & \\
Control & 0.718 & & & \\
\hline Intervention & 0.684 & & & \\
\hline Diff (I-C)b & -0.034 & 0.017 & -1.99 & $0.047^{\star \star}$ \\
\hline Endline & & & & \\
\hline Control & 0.726 & & & \\
\hline Intervention & 0.759 & & & \\
\hline Diff (I-C)e & 0.033 & 0.014 & 2.4 & $0.016^{\star *}$ \\
\hline Diff-in-Diff[I-C)e-(I-C)b] & 0.068 & 0.022 & 3.06 & $0.002^{\star * *}$ \\
\hline
\end{tabular}

*indicates $p<0.05, * *$ significant at $p<0.01$, ** significant at $p<0.001 ;$ I=Intervention and $C=$ Control; + Model adjusted for age, sex, marital status, occupation, education and household wealth index

Source: Field Data, 2020

The results of bivariate and multivariate analysis regarding predictors for whether the respondents ingested the drugs or not among respondents in the intervention group pre- and post-the intervention. The results are presented inTable 7. Post the intervention, respondents with adequate knowledge about onchocerciasis ( $\mathrm{aOR}=3.17,95 \% \mathrm{Cl}=1.55-6.46$ ), those who perceived the MDA drug as beneficial ( $\mathrm{aOR}=5.57,95 \% \mathrm{Cl}=1.26-24.68)$ and those who have previously participated in MDA programs $(\mathrm{aOR}=2.53,95 \% \mathrm{Cl}=1.17-5.48)$ had a significant increased odd of ingesting the drugs. Also, respondents who were living with their spouses $(\mathrm{aOR}=2.68,95 \% \mathrm{Cl}=1.00-7.16)$ were more than two times likely to ingest the MDA drugs they received. Furthermore, respondents who were in the high quintile category had lower odds of ingesting the MDA drug received as compared to those in the low quintile ( $\mathrm{aOR}=0.32,95 \% \mathrm{Cl}=0.14-0.75)$

Table 8: Bivariate and multivariate logistic regression of intervention effect on whether respondents ingested the drugs or not 
Factor

Baseline

Endline

$\operatorname{cOR}(95 \% \mathrm{Cl}) \quad \operatorname{aOR}(95 \% \mathrm{Cl}) \quad \operatorname{cOR}(95 \% \mathrm{Cl}) \quad \mathrm{aOR}(95 \% \mathrm{Cl})$

\section{Age category}

\begin{tabular}{lllll}
$18-29$ & Ref & Ref & Ref & Ref \\
\hline $30-39$ & $1.53(0.75-3.13)$ & $1.26(0.38-4.16)$ & $1.43(0.66-3.08)$ & $1.32(0.48-3.60)$ \\
\hline $40-49$ & $1.53(0.68-3.43)$ & $2.34(0.65-8.40)$ & $2.49(0.78-8.00)$ & $1.82(0.53-6.26)$ \\
\hline $50-59$ & $6.38(1.33-30.67) *$ & $\begin{array}{l}19.00(2.33- \\
154.69) \star \star\end{array}$ & - & - \\
\hline $60+$ & - & - & $3.12(0.71-13.68)$ & $2.46(0.31-$ \\
\end{tabular}

Sex

\begin{tabular}{lllll} 
Male & Ref & Ref & Ref & Ref \\
\hline Female & $1.06(0.52-2.15)$ & $1.30(0.62-2.76)$ & $0.78(0.36-1.65)$ & $0.63(0.28-1.40)$
\end{tabular}

Marital status

Single/widowed/Divorced

$\operatorname{Re}$

Ref

Ref

Ref

Living with Spouse

$1.34(0.74-2.44) \quad 1.22(0.52-2.84)$

$2.81(1.20-6.56)^{\star} \quad 2.68(1.00-7.16) *$

Occupation

Unemployed

Skilled labour

Ref

Ref

Ref

Ref

Unskilled labour

$0.65(0.27-1.60) \quad 1.03(0.3-3.1)$

0.76(0.23-2.54)

0.86(0.23-3.24)

$0.45(0.23-0.88)$ *

$0.2(0.1-0.6)$ **

$0.48(0.16-1.42)$

$0.41(0.11-1.62)$

\section{Educational status}

No formal education

Basic

Ref

Ref

Ref

Ref

$0.57(0.21-1.60)$

$1.64(0.54-5.02)$

$0.82(0.18-3.66)$

2.00(0.27-

14.72)

Secondary and above

$0.30(0.10-0.88)$ * $\quad 0.89(0.28-2.85)$

$0.61(0.14-2.73)$

2.57(0.31-

21.16)

\section{Household Wealth Index}

Low quintile

High quintile

\section{Duration of stay in the}

Community

Up to ten years

More than ten years

\section{Ever heard of Oncho}

Yes

$\begin{array}{llcll}\text { No } & \text { Ref } & \text { Ref } & \text { Ref } & \text { Ref } \\ \text { Yes } & 1.25(0.65-2.43) & 0.76(0.35-1.66) & 0.80(0.28-2.34) & 0.39(0.11-1.45) \\ & & \text { Page } 17 / 21\end{array}$

Ref

$1.07(0.57-2.01)$

Ref
$0.56(0.28-1.11)$

Ref

0.38(0.19-

$0.78)^{\star \star}$
Ref

$0.32(0.14-$

$0.75)^{\star \star}$ 


\section{Knowledge of Oncho}

\begin{tabular}{lllll} 
Indequate & Ref & Ref & Ref & Ref \\
\hline Adequate & $1.25(0.57-2.72)$ & $2.71(1.08-6.75) \star$ & $2.76(1.38-$ & $\begin{array}{l}3.17(1.55- \\
6.46)^{\star \star}\end{array}$
\end{tabular}

Aware of MDA

\begin{tabular}{lllll} 
No & Ref & Ref & Ref & Ref \\
\hline Yes & $1.73(0.68-4.35)$ & $0.39(0.13-1.21)$ & $1.67(0.69-3.99)$ & $1.01(0.39-2.65)$
\end{tabular}

MDA drug beneficial

\begin{tabular}{lllll}
\hline No & Ref & Ref & Ref & Ref \\
\hline Yes & $5.00(1.99-$ & $4.75(1.83-12.32)^{\star \star}$ & $8.02(2.35-$ & $5.57(1.26-$ \\
& $12.59)^{\star *}$ & & $27.39)^{\star *}$ & $24.68)^{*}$
\end{tabular}

Participated in previous MDA

$\begin{array}{lllll}\text { No } & \text { Ref } & \text { Ref } & \text { Ref } & \text { Ref } \\ \text { Yes } & 9.33(4.68- & 16.08(7.31- & 2.18(1.09-4.36)^{\star} & 2.53(1.17-5.48)^{\star} \\ & 18.62)^{\star \star \star} & 35.40)^{\star \star \star} & & \end{array}$

*indicates $p<0.05, * *$ significant at $p<0.01, * * *$ significant at $p<0.001$

\section{Discussion}

In the current study, MDA coverage was assessed within a two-year period (2019 and 2020) and the findings showed that MDA coverage had increased in 2020 compared with 2019 in both the intervention and control group. Although there was an increase in MDA coverage in the control group, MDA coverage had substantially increased in the intervention group in the 2020 round of MDA. These findings contradict with the reports of Griswold et al. which reported poor coverage of MDA in subsequent years over a three-year period (Griswold et al., 2018). The slight improvement in MDA coverage among the control group could be attributed to inter-community travels since the intervention and control communities nearly share boundaries. Further, we observed drastic reduction in the proportion of respondents who did not receive the drugs among the interventional group compared with the control group in the 2020 round of MDA. These outcomes concur with the reports of several studies which implemented various interventions and as a result influenced many community members to receive the MDA drugs (Deardorff et al., 2018; Koroma et al., 2018; Meribo et al., 2017).

Apparently, the improvement in coverage was due to the MDA SBCC intervention that was implemented prior to the MDA in 2020. Even though an intervention focused on improving supervision and monitoring was implemented in the report by Griswold et al. this did not significantly cause a change in and/or improve MDA coverage in both the interventional and control groups. This may imply that interventions must also aim at changing the attitude or behaviour of community members by disease specific sensitization or education. Several reasons such as not being aware of the drug distribution, CDD did not come to the house and drug not offered and absent from home were the most cited for not receiving the drugs thereby explaining the low coverage during 2019 round of MDA. Nonetheless, there was a reduction in the proportion of respondents who cited these reasons including a significant difference among the intervention group with respect to reasons such as not being aware of the drug distribution and CDD did not come to the house during the 2020 round of MDA. Prior to the 2020 round of MDA, CDDs were offered a rigorous training and were effectively supervised during the MDA exercises. Moreover, the number of CDDs increased during the 2020 round of MDA which 
may explain the significant changes. These findings concord with the outcomes of other studies wherein adequate training and equipment of CDDs improved MDA coverage (Kusi et al., 2020; Macfarlane et al., 2019).

Moreover, it was shown that respondents in the intervention group who are having adequate knowledge about onchocerciasis, perceived the MDA drug as beneficial, participation in previous MDA campaigns and being aware of the MDA program were more likely to receive the MDA drugs from the CDD after the intervention. The observations of this study were consistent with a similar study conducted in Ghana which revealed that improved knowledge on lymphatic filariasis and community perception about MDA and the disease among community members would enhance uptake of drugs (Manyeh et al., 2020). The findings were also consistent with other studies conducted in Africa (Richards et al., 2016). Overall, it was deduced that in the intervention group, receiving an intervention likely increased the MDA coverage in the community by $12.3 \%$, which may suggest that this significant difference would have not been the situation if the community members had not received the MDA SBCC intervention.

According to the $\mathrm{WHO}$, elimination of onchocerciasis in endemic areas can be achieved when elimination programs such as MDA attain at least $80 \%$ of compliance. In this study, the compliance to MDA was generally higher than the WHO minimum target which suggest that Ghana is on course to eliminate onchocerciasis. There was a significant improvement in the proportion of respondents in the intervention group who received and ingested the drugs in the 2020 round of MDA. The rate of compliance reported by this study during the 2020 round of MDA among the intervention group was higher than most studies conducted in Africa (Ahorlu et al., 2018; Brieger et al., 2011; Kamga et al., 2018). Obviously, the significant improvement of compliance among the intervention group in the current study could be attributed to the intervention that was implemented.

There was a substantial improvement in the proportion of respondents in the intervention group who swallowed the drugs in the presence of the CDD during the MDA in 2020 compared with MDA in 2019. This contradicts with the observations of other studies wherein majority of community receive drugs but refused to swallow drugs due to the fear of side effects (Agyemang et al., 2018; Dicko et al., 2020; Senyonjo et al., 2016). Therefore, in this present study the change in attitude towards the ingestion of the drugs was largely influenced by MDA SBCC implemented prior to the 2020 MDA exercise. Furthermore, a significant improvement in the uptake of the drugs among household and perception of the drug being beneficial was recorded post-intervention (MDA in 2020). Overall, the CEM technique showed that there was a significant increase in drug uptake during the 2020 round of MDA and therefore, there was likely $5.4 \%$ increase in drug uptake among the community members upon receiving the intervention. It was therefore, averred that the significant difference can be attributed to the MDA SBCC intervention. It could also be argued that this intervention had scaled-up trust and hence the implementation of this intervention would enhance community trust in the existing public health systems.

Post the intervention, respondents who perceived drugs as beneficial, those with adequate knowledge about onchocerciasis, those who have previously participated in MDA programs and those who were living with their spouses were more likely to ingest the drugs. These observations were consistent with other studies conducted in the African setting (Krentel et al., 2017; Manyeh et al., 2020). According to Njomo et al. (2012), community members in high quintile were more compliant to MDA. However, their observations contradict with the findings of this study wherein it was revealed that respondents in the high quintile were less likely to ingest drugs during MDA.

Recall bias was a possibility since respondents were required to recall information about the MDA campaign that had been completed two months ago. In order to minimize the recall bias, the data was collected about a month after the MDA campaign.

\section{Conclusion}


The findings of this study reveal that SBCC intervention improves ivermectin coverage and uptake rate in mass drug administration. Factors that significantly improve the coverage and compliance of ivermectin includes; Having adequate knowledge about onchocerciasis, perceived benefit of the MDA drug, participation in previous MDA campaigns and being aware of the MDA program. Further research with technological innovations which can enhance SBCC is recommended taking hind sight of the limitations of the study due to the COVID-19 pandemic.

\section{Declarations}

\section{Funding:}

The work was funded by DANIDA under the Building Stronger Universities (BSU) initiative - Work Package III (Health Delivery System) issued by the KNUST Office of Grants and Research.

\section{Availability of data and materials}

The data and materials are available in the corresponding author's institution and will be made available upon formal request

\section{Author Contributions}

FAO, SN, EO-D, PF, DWM had the original idea of the study. EOY, SFO, NMK, IN, SYA, OON, AM, AM, OA, SB, EA and EXA were responsible for the data collection, data cleaning and analysis. FAO drafted the initial manuscript. EO-D and SN supervised the project. DM, PF, SN, EOY, AM, IN, EXA and EO-D revised the draft manuscript and ensured that the grammar and use of terms were appropriate within the context. All authors read and agreed to the final manuscript and will be accountable for it.

\section{Ethics approval and consent to participate}

The study was explained to the participants and caregivers in clear and unambiguous language. Written informed consent was obtained before inclusion in the study. Ethical approval was obtained from the KNUST Committee on Human Research Publications and Ethics (CHRPE/AP/001/19) and permission was sought from the District Health Directorate.

\section{Consent for publication}

Not applicable

\section{Conflicts of Interest:}

The authors declare no conflicts of interest

\section{Acknowledgments:}

We wish to acknowledge the respondents of this study for their time

\section{Figures}




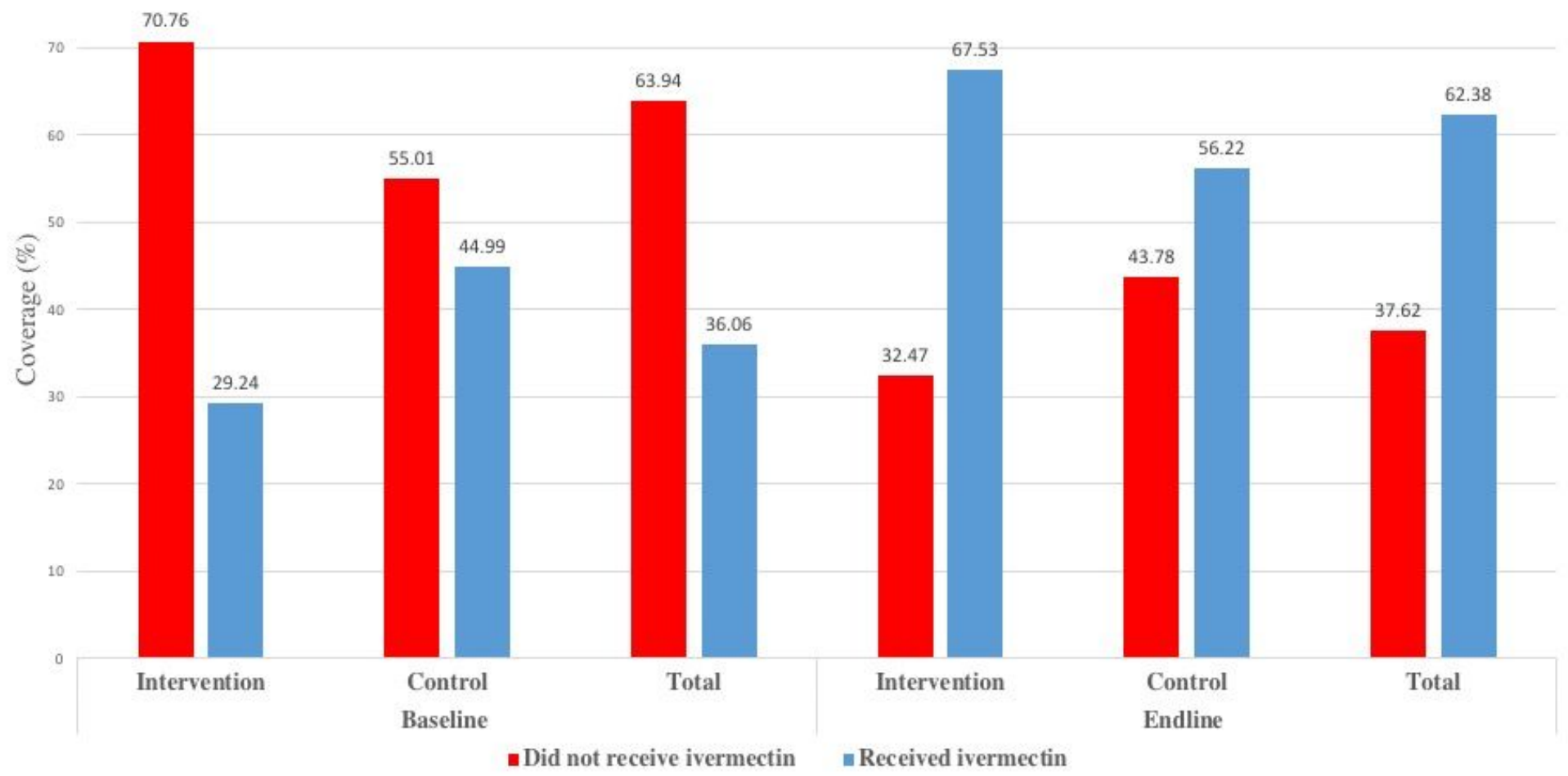

Figure 1

Coverage of MDA (Received or not received ivermectin) at baseline and endline

120

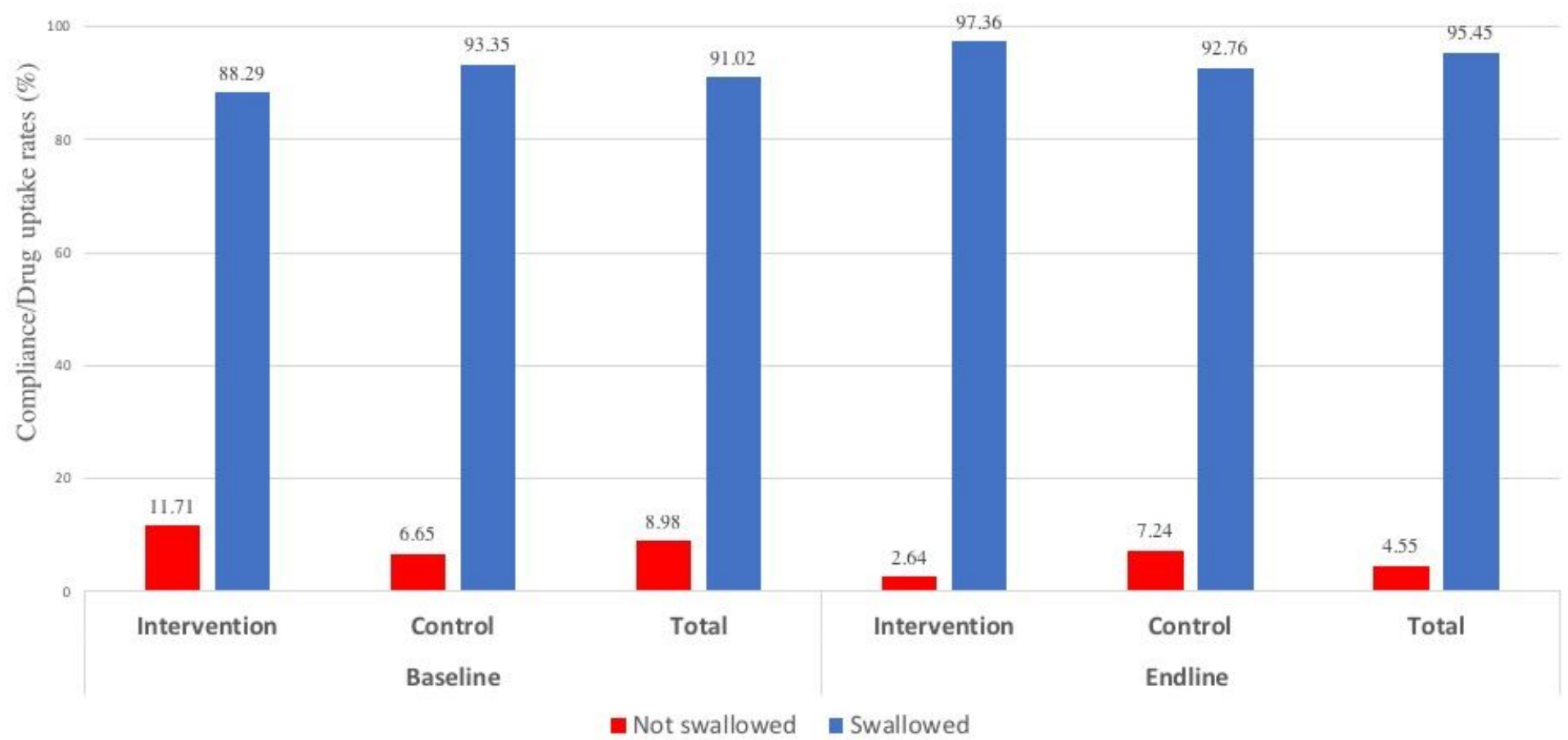

Figure 2

Compliance (uptake of ivermectin) at baseline and endline 